\title{
Diagnóstico e tratamento em neurologia infantil
}

\author{
Diagnosis and treatment in pediatric neurology
}

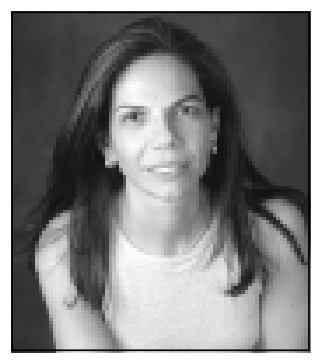

Magda Lahorgue Nunes ${ }^{1}$

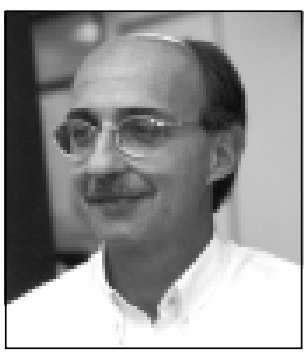

José Luiz Dias Gherpelli ${ }^{2}$

$\mathbf{O}$ suplemento Diagnóstico e tratamento em neurologia infantil trata de temas que são de grande importância para o pediatra. A prevalência dos assuntos abordados evidencia a frequiência com que estes devem ser encontrados na prática pediátrica diária.

Admitindo-se que os dados epidemiológicos sejam comparáveis, a despeito de variações que ocorrem dependendo de regiões e etnias estudadas, e frente à persistente ausência de dados da população pediátrica brasileira no que concerne a diversos dos temas revisados, é possível estimar que a prevalência de cefaléias é de $40 \%$ em crianças abaixo de 10 anos de idade, as convulsões febris, de 3 a $4 \%$, o transtorno do déficit de atenção, de 5 a 15\%, a paralisia cerebral, de $0,5 \%$, a epilepsia, de $1 \%$, a deficiência mental (freqüentemente associada a síndromes disgenéticas), de $1 \%$, e os distúrbios do sono, de 3 a $7 \%$. Além disso, o trauma craniencefálico e o primeiro episódio isolado de crise convulsiva persistem sendo importante causa de consulta nas emergências pediátricas. O correto encaminhamento para o diagnóstico e tratamento destas patologias é fundamental, tanto em nível de emergência ou ambulatorial, para que estas crianças tenham uma melhor qualidade de vida e bem-estar.

1. Prof ${ }^{a}$ Adjunta Doutora do Departamento de Pediatria e Medicina Interna/Neurologia da Faculdade de Medicina da Pontifícia Universidade Católica do Rio Grande do Sul.

2. Livre Docente em Neurologia Infantil pela Faculdade de Medicina da USP (FMUSP). Médico Assistente do Serviço de Neurologia Infantil e responsável pelos Ambulatórios de Neurologia do Desenvolvimento e de Cefaléias na Infância e Adolescência, do Hospital das Clínicas da FMUSP, São Paulo, SP. Neuropediatra do Hospital Israelita Albert Einstein, São Paulo, SP. 
As doenças neuromusculares, apesar de relativamente mais raras quando comparadas às anteriormente citadas, foram abordadas devido ao avanço significativo das técnicas empregadas para o seu diagnóstico. Como a maioria delas apresenta etiologia genética, a sua correta identificação é fundamental para o pediatra estar capacitado a orientar a família quanto a aspectos prognósticos, terapêuticos e aconselhamento genético.

As epilepsias de difícil controle medicamentoso, que correspondem a mais ou menos $20 \%$ das epilepsias em geral, tiveram seu panorama modificado com os avanços nas técnicas de neuroimagem e neurocirúrgicas, possibilitando uma nova alternativa terapêutica com excelentes resultados em casos selecionados.

Foi nosso objetivo, ao selecionarmos temas e autores para este suplemento, proporcionar ao pediatra uma atualização didática sobre temas prevalentes, e que necessitam de pronto reconhecimento e atuação em nível de cuidados primários e terciários. 